Spring 2010

\title{
Preservice teachers' self-perceptions and attitudes toward culturally responsive teaching
}

\author{
Barbara Frye \\ Linda Button \\ Catherine Kelly \\ Greg Button
}

Follow this and additional works at: https://digitalscholarship.unlv.edu/jpme

\section{Repository Citation}

Frye, Barbara; Button, Linda; Kelly, Catherine; and Button, Greg (2010) "Preservice teachers' selfperceptions and attitudes toward culturally responsive teaching," Journal of Praxis in Multicultural Education: Vol. 5: No. 1, Article 5.

DOI: $10.9741 / 2161-2978.1029$

Available at: https://digitalscholarship.unlv.edu/jpme/vol5/iss1/5

This Article is protected by copyright and/or related rights. It has been brought to you by Digital Scholarship@UNLV with permission from the rights-holder(s). You are free to use this Article in any way that is permitted by the copyright and related rights legislation that applies to your use. For other uses you need to obtain permission from the rights-holder(s) directly, unless additional rights are indicated by a Creative Commons license in the record and/ or on the work itself.

This Article has been accepted for inclusion in Journal of Praxis in Multicultural Education by an authorized administrator of Digital Scholarship@UNLV. For more information, please contact digitalscholarship@unlv.edu. 


\title{
Preservice Teachers' Self-Perceptions and Attitudes Toward Culturally Responsive Teaching
}

\author{
Barbara Frye, Linda Button, Catherine Kelly, and \\ Greg Button
}

\begin{abstract}
When infusing Culturally Responsive Teaching (CRT) concepts in preservice methods classes, teacher candidates (TCs) begin a journey that involves understanding the cultural contributions of the students in the classroom, as well as becoming aware of the possible disconnects between their cultures and the culture of the school. To help preservice teachers learn how to bridge these gaps, teacher education faculty integrated history, literacy, and art into a literacy methods course as a first step in helping teacher candidates develop the necessary competencies to successfully implement culturally responsive teaching in their own classrooms. Four university faculty members administered an adapted version of The Culturally Responsive Teaching Self Efficacy and The Culturally Responsive Teaching Outcome Expectancies Scales (Siwatu, 2007) to 55 teacher candidates $(n=55)$, and had them selfevaluate and rank their beginning competencies, and define what strategies and knowledge they wanted to gain during the semester. At the end of the semester, TCs re-evaluated themselves on the same survey, and then reflected on their experiences. Teacher candidate responses on the survey indicate that they perceived themselves as gaining knowledge and skills in their ability to understand and implement culturally responsive pedagogy. The TCs were also positive about their experiences in this project.
\end{abstract}

When infusing Culturally Responsive Teaching (CRT) concepts in methods classes, teacher candidates begin a journey that involves understanding the cultural contributions of the students in the classroom, as well as becoming aware of the possible disconnects between students' cultures and the culture of the school. It is important for preservice teachers to understand the concept that "everyone has a culture" (Gay, 2010). There are substantive things teacher educators can do to get teacher candidates, and ultimately students in classrooms, to be more inclusive of each other. First and foremost they must learn to value both themselves and others. To help teacher candidates learn how to bridge the cultural gaps between home and school, four university faculty members administered an adaptation of Siwatu's (2007) Culturally Responsive Teaching Self-Efficacy (CRTSE) and Culturally Responsive Teaching Outcome Expectancy (CRTOE) scales to 55 elementary teacher candidates $(n=55)$ in two literacy methods classes (one graduate and one undergraduate), and had them self evaluate and rank their beginning competencies, and define what strategies and knowledge they wanted to gain during the semester. At the end of the 
semester teacher candidates reevaluated themselves on the same survey after they participated in a methods class infused with CRT pedagogy.

The purpose of this paper is to describe how history, literacy and art were integrated in the college classroom and then taught in elementary classrooms by the teacher candidates as a first step in becoming culturally responsive. At the end of the semester, the candidates re-evaluated themselves using the same survey, and then reflected on their experiences, the competencies they had gained and the skills and knowledge they still wanted to learn to become culturally responsive to future students. Much of the current work in the area of measurement of CRT effectiveness has been derived from the work of Bandura (1993; 1997) including Social Cognitive Theory (Bandura, 1977). His work suggests that preservice teachers' beliefs about their abilities to effectively execute CRT strategies and project subsequent positive outcomes may predict whether they actually implement these culturally responsive teaching practices once they enter the classroom. Bandura's research in self-efficacy has also been used extensively in assessing teacher effectiveness. Self-efficacy is defined as "beliefs in one's capabilities to organize and execute the courses of action required to produce given attainments" (Bandura, 1997, p. 3).

In the study and implementation of culturally responsive pedagogy with both novice and veteran teachers, it is essential to connect it to events in teaching and learning that (1) use students' cultural knowledge (e.g., culturally familiar scenarios, examples, and vignettes) experiences, prior knowledge, and individual learning preferences as a conduit to facilitate the teaching-learning process (curriculum and instruction); (2) incorporate students' cultural orientations to design culturally compatible classroom environments (classroom management); (3) provide students with multiple opportunities to demonstrate what they have learned using a variety of assessment techniques (student assessment); and (4) provide students with the knowledge and skills needed to function in mainstream culture while simultaneously helping students maintain their cultural identity, native language, and connection to their culture (cultural enrichment and competence) (Siwatu, 2007, pp. 1086-1087). Along with these premises, others have projected a clear alignment among performance standards and teacher education curricula, and the demonstration of competencies in preservice teachers prior to graduation (Hilliard, 1998). Although, in some cases, Siwatu (2007) suggests that this is not necessarily a predictor of how these same preservice teachers will address CRT in their classrooms later on.

Other research has defined characteristics of effective pedagogy in efforts to prepare culturally responsive teachers, including (a) developing a caring attitude, (b) establishing assertiveness and authority, (c) demanding effort, (d) establishing congruent communication processes, (e) enhancing meaning, and (f) engendering competence in the classroom with all students (Brown, 2004;Wlodkowski \& Ginsberg, 1995). These authors suggest that the 
best culturally responsive teachers show warmth and affection to students and give priority to the development of relationships with students as a way to enhance student growth (Brown, 2004). This may imply that if teachers genuinely care for their students, then students might be more apt to care more about learning (Jones, 2007). An effective, caring teacher who uses CRT in the classroom presents information in a way that helps students connect their knowledge and experience to the new learning for better comprehension and by establishing a relationship that shows he or she cares about his or her students and wants them to succeed (Bennett, 2008). Additionally, it is important to note that many students who are ethnically diverse experience assertive authority at home and expect teachers to have a similar authoritative stance at school. These students are more likely to succeed in a classroom where the teachers understand this and adjust their management style accordingly (Wlodkowski, \& Ginsberg, 1995). Important also is the teacher's understanding of the communication processes of all students since this is a clear indictor of a caring attitude for students. A culturally responsive teacher will make the effort to understand all the cultures, communication styles, and communication processes of their students. Being a culturally responsive teacher means making learning relevant for students by including real life experiences that students can relate to when creating background (Jones, 2007). When effective CRT occurs, the teacher engenders student competence when he/she facilitates student learning that is important and significant to them. Specifically this might include creating lessons that include multiple entry points and differentiated learning strategies, learning styles, and languages, encouraging choice and individuality in the classroom, and varied choice in assignments and assessment methods to show what they have learned (Joyce, Weil, \& Calhoun, 2009).

\section{The Culturally Responsive Teaching Self-Efficacy and Outcome Expectancy Scales}

The development of the Culturally Responsive Teaching Self-Efficacy (CRTSE) and the Culturally Responsive Teaching Outcome Expectancy (CRTOE) scales (Siwatu, 2007) was driven by (1) the study of culturally responsive teacher preparation and teacher efficacy research; (2) the realization that there was a minimal amount of available research on the examination of preservice and inservice teachers' culturally responsive teaching self-efficacy; and (3) outcome expectancy beliefs and, the need for useful tools for program administrators and teacher educators to use in assessing program effectiveness.

Based on the review of the literature, it seems that there are no excuses for not making overt attempts to infuse culturally responsive pedagogy in teacher education programs. Training in CRT is essential to remaining 
committed to the achievement of all students and it is a dynamic growth process that requires continuous work in the career of a teacher. While it may be said that culturally responsive teaching is simply good teaching, faculty in colleges of education cannot assume that teacher candidates will develop the skills necessary to be culturally responsive to their students and develop classroom environments and curricula that is culturally relevant without explicitly addressing these issues in teacher education classes. Passion, dedication, and commitment are vital in implementing CRT practices in the classroom and preservice teaching must embed instruction and activities which give teacher candidates opportunities to explore their own beliefs, develop an awareness and understanding of the diverse nature of today's classrooms, and to learn how to be culturally responsive to the members of their school community. There is evidence that some teacher candidates will maintain biases even with training in multicultural competence (Sammons \& Speight, 2008). This is a substantial barrier to overcome in the development of culturally responsive teaching, but should not deter efforts to develop teacher education programs that produce teachers with a sensitivity to students' differences and a commitment to meeting the academic needs of all students through culturally relevant teaching.

The current study, therefore, was designed to look at the preservice teachers' beliefs about their self-efficacy and outcome expectancies for cultural responsive teaching prior to and after participating in a methods class infused with cultural responsive pedagogy. Because the relationship between preservice teachers' beliefs about what they know about CRT and what they can implement plays such an important role in their success as teachers (Bandura, 1997; Siwatu, 2007), the relationship between the teacher candidates' self-efficacy ratings and their expectations for teaching outcomes was examined. Additionally, since history, literacy, and art were used as vehicles with which to explore culturally relevant and responsive teaching, it was also important to collect data about teacher candidates' reactions and ideas about this approach.

\section{Method}

The faculty members or researchers involved in this project adapted Siwatu's (2007) Culturally Responsive Teaching Self-Efficacy and Outcome Expectancy scales for the purpose of this study. These instruments or self-assessment surveys were used as pre and post measures of culturally responsive teaching competencies the teacher candidates had at the beginning of the study and then gained over a sixteen week period as a result of activities, strategies and lessons in the college classroom and at their professional development schools. There were 32 undergraduate and 24 graduate teacher candidates enrolled in two elementary literacy methods classes at a comprehensive regional research university located in the western part of the United States who participated in 
the study. The faculty members in the teacher education program have made a commitment to infuse CRT into all methods courses in addition to the program seminars devoted to this topic. One of the researchers was the instructor for the two literacy methods courses involved in this study. While the teacher candidates were required to participate, they were assured that they would not be graded on their responses, just for participation. Furthermore, anonymity was guaranteed and the data cannot be traced back to individual students. The participants were White (50), Latino (4), African American (1), and Pacific Islander (1). One White graduate student withdrew from the class for unrelated reasons, so the total number of participants was 55, with a response rate of $100 \%$.

\section{The Survey/Self Assessment}

The survey or self assessment was comprised of four parts. Part I: Culturally Responsive Teaching Competencies ("I am able to," and "Students will") required a narrative response by the teacher candidates. Parts II and III: Current Knowledge and Skills and Teaching the Skills to Students had a total of sixtysix items. Part II had 40 questions based on Siwatu's (2006) Culturally Responsive Teaching Self-Efficacy Scale (CRTSE) and Part III had 26 items based on Siwatu's (2006) Culturally Responsive Teaching Outcome Expectancy (CRTOE). For this section of the assessment, the candidates self rated their current knowledge and ability in teaching skills to students from 0 (lowest) to 100 (highest). A total score and mean score were calculated for the items. Part IV: Self-Analysis asked the candidates to review their own responses and then "condense" the competencies/skills in rank order (from 1-10) based on their own scoring in order to frame what competencies they would most like to gain during the semester in order to meet the needs of all students in the classroom. For the purpose of this study, only Section II (CRTSE) and Section III (CRTOE) were analyzed. The teacher candidates took the survey again at the end of the semester as a posttest to determine what competencies they had gained, and what competencies they wanted to enhance and acquire in the next semester when they would be fulltime student teaching.

\section{Procedures}

Working with preservice teachers in both the literacy methods classes and at the professional development sites provided the faculty members involved with the opportunity to introduce and model culturally responsive reading, writing, thinking, viewing and creating processes and teaching strategies. The candidates also kept journals which invited them to reflect on their teaching practices, the 
children's and clinical teachers' attitudes and responses, and their reflections on the lessons and classroom climate.

The unit or project began with a book read aloud to the class titled Henry's Freedom Box (2007), a Caldecott Honor Book written by Helen Levine and illustrated by Kadir Nelson. The book recounts the true story of Henry Brown, who was born a slave in the mid 1800 s, and devised a plan which gained him freedom by hiding in a box his friends nailed shut, mailed to Philadelphia, and thus to freedom. After the class discussed the book and the courageous actions of Henry and his friends, the researchers read aloud a second picture book and also a Caldecott Honor Book, Tar Beach (1991) written and illustrated by Faith Ringgold. The book, a fantasy, tells the story of a young African American girl living in Harlem during the Depression era who dreams of flying above her home to see the sights and sounds of her city and neighborhood. The story and illustrations, based on the actual story quilt that Ringgold created in 1988 , portray a very fanciful, lyrical, and symbolic form of freedom. The two books together present very different views of individual experiences and freedom for African Americans over a span of one hundred and fifty years. The objective was for teacher candidates to connect the concepts of freedom and slavery to real events as well as creative expression. The larger goal of the project was to provide the preservice teachers an opportunity to participate in a CRT lesson in order to learn a variety of teaching methods designed to meet the varying needs of students. This experience taught the teacher candidates the importance of incorporating knowledge about different cultures when schools may not be culturally diverse, accepting the unique qualities of all people, and helping students appreciate and affirm their own heritages and feel as though they are each valued members of the community.

After reading and discussing these two picture books about African American culture, a group that is underrepresented in our teacher education program, two of the researchers co-taught an art and literacy project. The instruction began with a visual presentation of how symbols and designs are used to express an individual's or group's heritage, accomplishments and those things cherished in our lives. Next, one of the researchers, an art specialist, demonstrated the use of different art materials and media, as well as color and line to express a person's unique identity. The teacher candidates then developed their own paper quilt squares using markers, crayons, photos and other media. Each square contained three or four symbols that expressed who the candidates were in terms of their interests, cultures, and unique characteristics. At the end of the project, the quilt squares were put together to form a collage comprised of everyone's quilt square in the class. When the quilt was complete, the candidates commented on how all the pieces fit together perfectly, and how beautiful the colors and symbols were, both separately and together. The class collage/quilt was photographed by the researchers and put into a slide show that the class 
viewed and discussed later. It should be noted that even though the candidates liked the quilt "in toto," it was very important for them to keep their own quilt squares so they could remember the project and then share what they made with the students in the elementary classrooms.

The candidates were encouraged to develop similar projects and ideas for their own teaching, and they described in their journals what they thought of the project, and how they incorporated culturally responsive knowledge and skills into literacy and social studies lessons and other classroom learning activities. At the end of the semester, the candidates were given the same survey as a posttest to determine what knowledge, skills and competencies they had gained, and what competencies they still wanted to refine and acquire.

\section{Results}

This study focused on ascertaining preservice teachers' self perceptions about their own knowledge about culturally responsive teaching and their ability to provide instruction that would meet the needs of a diverse group of students prior to and after participating in the CRT project in the literacy methods class. Pre and posttests were analyzed and it was clear that preservice teachers perceived their knowledge level and teaching abilities in terms of culturally responsive teaching to improve over the sixteen- week semester. Teacher candidates were asked to rate themselves on a 100-point scale for each question that one might think of as a percentage scale. When analyzing the TCs' responses, their self-ratings fell into bands that easily transferred to a sevenpoint scale. Responses of 90-100 were given a score of $7,75-89=6,60-74=5$,

Figure 1

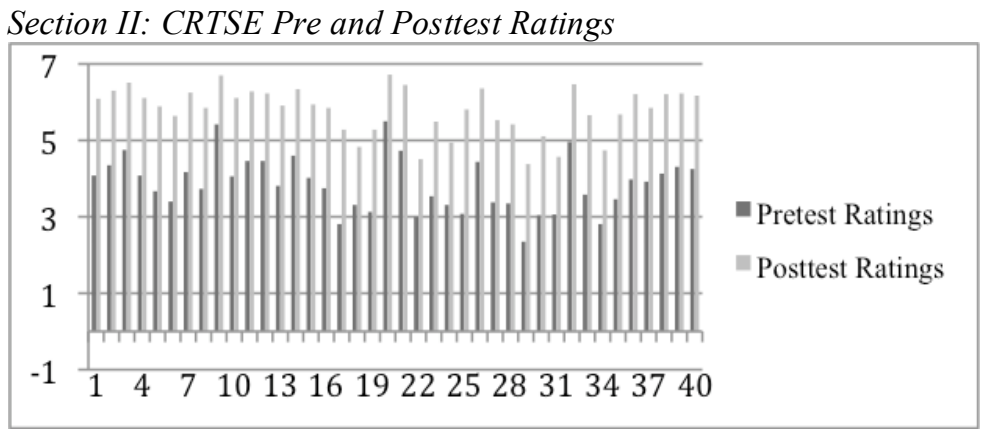

Figure 1. This graph illustrates the change in self-perceptions of teacher candidates on the 40 questions in Section II (CRTSE) of the survey from pretest to posttest. The Culturally Responsive Teaching Outcome Expectancies scale adapted from Siwatu's (2007) scale of the same name. 
$45-59=4,30-44=3,15-29=2$, and $0-14=1$. On Part II of the CRTSE section of the survey, teacher candidates rated themselves an average score of 3.86 on the pretest and 5.80 on the posttest showing a considerable growth in their belief that they possess the knowledge and skills necessary to be culturally responsive to their students. Figure 1 shows the relationship between the teacher candidates' pre and posttest scores on Section II (CRTSE).

On Part III (CRTOE) section of the survey, the preservice teachers rated themselves an average score of 3.92 on the pretest and a 5.90 on the posttest. Again, this shows perceived growth over the 16-week class. It is interesting to note that the participants rated themselves quite similarly on their self-efficacy and outcome expectancies on both the pretest and posttest. Figure 2 shows the relationship between the teacher candidate's pre and posttest scores on Section III (CRTOE).

The list of questions for Sections II (CRTSE) and III (CRTOE) of the survey with teacher candidates' pre and posttest ratings for each question are provided in Tables 1 and 2 .

Figure 2

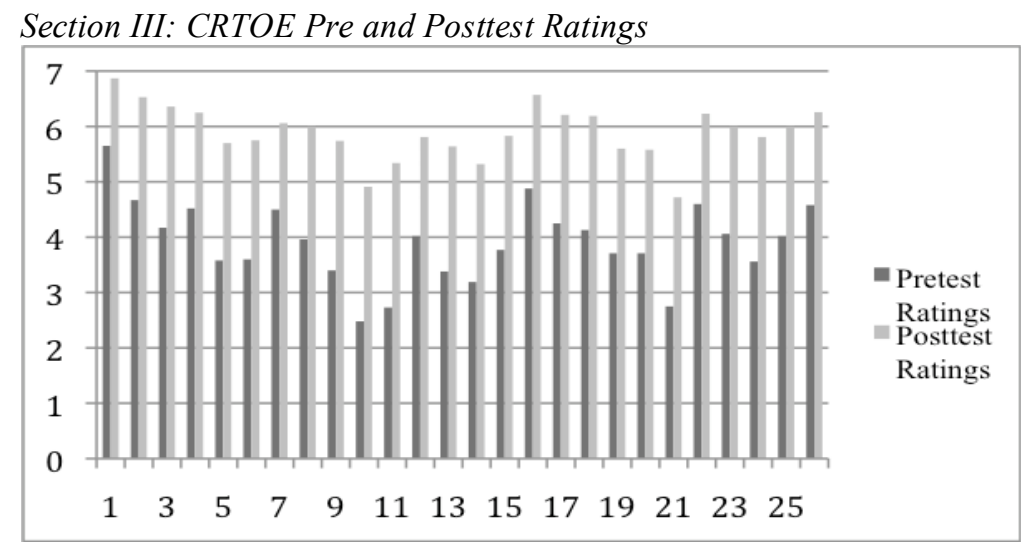

Figure 2. This graph illustrates the change in self-perceptions of teacher candidates on the 26 questions in Section III (CRTOE) of the survey from pretest to posttest. The Culturally Responsive Teaching Outcome Expectancies scale adapted from Siwatu's (2007) scale of the same name. 
Table 1

Pretest Posttest Means for items on the CRTSE Scale

\begin{tabular}{|c|c|c|c|}
\hline Item & & Pretest $M$ & Posttest $M$ \\
\hline 1 & I am able to adapt instruction to meet the needs of my students. & 4.08 & 6.09 \\
\hline 2 & $\begin{array}{l}\text { I am able to obtain and use information about my students' academic } \\
\text { strengths. }\end{array}$ & 4.35 & 6.30 \\
\hline 3 & $\begin{array}{l}\text { I am able to determine whether my students like to work alone or in a } \\
\text { group. }\end{array}$ & 4.75 & 6.51 \\
\hline 4 & $\begin{array}{l}\text { I know whether or not my students feel comfortable competing with } \\
\text { other students. }\end{array}$ & 4.08 & 6.11 \\
\hline 5 & $\begin{array}{l}\text { I am able to identify ways that the school culture (e.g. values, norms, } \\
\text { and practices) is different from my students' home culture. }\end{array}$ & 3.67 & 5.89 \\
\hline 6 & $\begin{array}{l}\text { I am able to implement strategies to minimize the effects of the } \\
\text { mismatch between my students' home culture and the school culture. }\end{array}$ & 3.4 & 5.64 \\
\hline 7 & $\begin{array}{l}\text { I am able to assess student I am able to assess student learning using } \\
\text { various types of assessments. }\end{array}$ & 4.17 & 6.25 \\
\hline 8 & I am able to gain relevant information about my students' home life. & 3.73 & 5.85 \\
\hline 9 & I am able to build a sense of trust in my students. & 5.42 & 6.70 \\
\hline 10 & $\begin{array}{l}\text { I am able to establish I am able to establish positive home-school } \\
\text { relations. }\end{array}$ & 4.06 & 6.11 \\
\hline 11 & $\begin{array}{l}\text { I use a variety of teaching I use a variety of teaching methods to help } \\
\text { meet the needs of all students. }\end{array}$ & 4.46 & 6.28 \\
\hline 12 & $\begin{array}{l}\text { I am able to develop a community of learners when my class consists } \\
\text { of students from diverse backgrounds. }\end{array}$ & 4.46 & 6.23 \\
\hline 13 & $\begin{array}{l}\text { I use my knowledge of I use my knowledge of students' cultural } \\
\text { background to help make learning meaningful. }\end{array}$ & 3.81 & 5.91 \\
\hline 14 & $\begin{array}{l}\text { I use my students' prior I use my students' prior knowledge to help } \\
\text { them make sense of new information. }\end{array}$ & 4.60 & 6.34 \\
\hline 15 & $\begin{array}{l}\text { I am able to identify the I am able to identify the ways students } \\
\text { communicate at home and know they may differ from the school } \\
\text { norms. }\end{array}$ & 4.02 & 5.94 \\
\hline 16 & $\begin{array}{l}\text { I am able to gain information about my students' cultural } \\
\text { backgrounds. }\end{array}$ & 3.75 & 5.85 \\
\hline 17 & I teach students about their cultures' contributions in the content areas. & 2.81 & 5.28 \\
\hline 18 & $\begin{array}{l}\text { I am able to greet English Language Learners with a phrase in their } \\
\text { native language. }\end{array}$ & 3.31 & 4.83 \\
\hline 19 & $\begin{array}{l}\text { I design a classroom environment using displays that reflect a variety } \\
\text { of cultures. }\end{array}$ & 3.13 & 5.28 \\
\hline 20 & $\begin{array}{l}\text { I develop a personal I develop a personal relationship with my } \\
\text { students. }\end{array}$ & 5.50 & 6.72 \\
\hline 21 & $\begin{array}{l}\text { I know how to obtain I know how to obtain information about my } \\
\text { students' academic weaknesses. }\end{array}$ & 4.73 & 4.51 \\
\hline 22 & $\begin{array}{l}\text { I am able to praise English Language Learners for their } \\
\text { accomplishments using a phrase in their native language. }\end{array}$ & 3.00 & 4.51 \\
\hline 23 & $\begin{array}{l}\text { Identify ways that standardized tests may be biased towards } \\
\text { linguistically diverse students. }\end{array}$ & 3.54 & 5.49 \\
\hline
\end{tabular}




\begin{tabular}{llll}
\hline 24 & $\begin{array}{l}\text { I regularly communicate with parents regarding their child's } \\
\text { educational progress. }\end{array}$ & 3.31 & 4.94 \\
\hline 25 & $\begin{array}{l}\text { Structure parent-teacher conferences so that the meeting is not } \\
\text { intimidating for parents. }\end{array}$ & 3.08 & 5.81 \\
\hline 26 & $\begin{array}{l}\text { I am able to help students to develop positive relationships with their } \\
\text { classmates. }\end{array}$ & 4.44 & 6.36 \\
\hline 27 & $\begin{array}{l}\text { I revise instructional material to include a better representation of } \\
\text { cultural groups. }\end{array}$ & 5.38 & 5.53 \\
\hline 28 & $\begin{array}{l}\text { I critically examine the curriculum to determine whether it reinforces } \\
\text { negative cultural stereotypes. }\end{array}$ & 3.35 & 5.42 \\
\hline 29 & $\begin{array}{l}\text { I design a lesson that shows how other cultural groups have made use } \\
\text { of mathematics. }\end{array}$ & 2.35 & 4.38 \\
\hline 30 & $\begin{array}{l}\text { I demonstrate/model classroom tasks to enhance English Language } \\
\text { Learners' understanding. }\end{array}$ & 3.04 & 5.11 \\
\hline 31 & $\begin{array}{l}\text { I am able to communicate with the parents of English Language } \\
\text { Learners regarding their child's achievement. }\end{array}$ & 3.06 & 4.57 \\
\hline 32 & I help students feel like they are valued members of the classroom. & 4.96 & 6.47 \\
\hline 33 & $\begin{array}{l}\text { I am able to identify ways that standardized tests may be biased } \\
\text { towards culturally diverse students. }\end{array}$ & 3.58 & 5.66 \\
\hline 34 & $\begin{array}{l}\text { I use a learning preference or interest inventory to gather data about } \\
\text { how my students like to learn. }\end{array}$ & 2.81 & 4.74 \\
\hline 35 & $\begin{array}{l}\text { I use examples that are familiar to students from diverse cultural } \\
\text { backgrounds. }\end{array}$ & 3.46 & 5.68 \\
\hline 36 & $\begin{array}{l}\text { I explain new concepts using examples that are taken from my } \\
\text { students' everyday lives. }\end{array}$ & 3.98 & 6.21 \\
\hline 37 & I obtain information regarding my students' academic interests. & 3.92 & 5.85 \\
\hline 38 & $\begin{array}{l}\text { I am able to use the interests of my students to make learning } \\
\text { meaningful for them. }\end{array}$ & 4.13 & 6.21 \\
\hline 39 & $\begin{array}{l}\text { I implement cooperative learning activities for those students who like } \\
\text { to work in groups. }\end{array}$ & 4.31 & 6.23 \\
\hline 40 & I design instruction that matches my students' developmental needs. \\
\hline & \begin{tabular}{l}
4.25 \\
\hline
\end{tabular} & 6.17 \\
\hline
\end{tabular}

Table 2

Pretest Posttest Means for items on the CRTOE Scale

\begin{tabular}{|c|c|c|c|}
\hline Items & & Pretest M & Posttest M \\
\hline 1 & $\begin{array}{l}\text { I am able to establish positive teacher-student relationship by building } \\
\text { a sense of trust in my students. }\end{array}$ & 5.65 & 6.87 \\
\hline 2 & $\begin{array}{l}\text { I am able to incorporate a variety of teaching methods to help my } \\
\text { students to be successful. }\end{array}$ & 4.67 & 6.53 \\
\hline 3 & $\begin{array}{l}\text { I help my students to be successful by adapting instruction to meet } \\
\text { their needs. }\end{array}$ & 4.17 & 6.36 \\
\hline 4 & $\begin{array}{l}\text { I am able to develop a community of learners when my class consists } \\
\text { of students from diverse cultural backgrounds will promote positive } \\
\text { interactions between students. }\end{array}$ & 4.52 & 6.25 \\
\hline 5 & $\begin{array}{l}\text { I am able to acknowledge the ways that the school culture is different } \\
\text { from my students' home culture to help minimize the likelihood of }\end{array}$ & 3.58 & 5.70 \\
\hline
\end{tabular}


discipline problems.

6 I understand the communication preferences of my students which helps decrease the likelihood of student-teacher communication problems.

$3.60 \quad 5.75$

7 I am able to connect my students' prior knowledge with new incoming information will lead to deeper learning.

$4.50 \quad 6.06$

8 I am able to match instruction to the students' learning preferences to enhance their learning.

$3.96 \quad 6.00$

9 I am able to revise instructional material to include a better representation of the students' cultural group in order to foster positive self-images.

$3.40 \quad 5.74$

10 I provide English Language Learners with multi-media resources to enhance their understanding of assignments.

$2.48 \quad 4.91$

11 I design and teach lessons which include the contributions the cultures of the students have made over time so they will develop an

appreciation of their heritage. $2.73 \quad 5.34$ the classroom in order to increase parent participation. $4.02 \quad 5.81$

13 I am able to help decrease student-teacher misunderstandings because I understand my students' cultural backgrounds.

$3.38 \quad 5.64$

14 (14) I am able to change the structure of the classroom so that it is compatible with my students' home culture in order to increase their motivation to come to class.

$3.19 \quad 5.32$

15 I am able to establish positive home-school relations to help increase parental involvement.

$3.77 \quad 5.83$

16 I am able to develop a personal relationship between the students and me in order to increase student attendance.

$4.88 \quad 6.57$

17 I assess student learning using a variety of assessment procedures to gain a better picture of what they have learned.

$4.25 \quad 6.21$

18 I use my students' interests when designing instruction will increase their motivation to learn.

19 I am able to simplify the language used during teaching to enhance English Language Learners' comprehension of the lesson.

$3.71 \quad 5.60$

20 I interpret standardized test scores with caution to ensure that students' abilities are not misdiagnosed.

$3.71 \quad 5.60$

21 When appropriate, I encourage students to use their native language to help to maintain their cultural identity.

$3.71 \quad 5.58$

22 I value students' cultural background in order to support and enhance their self-esteem.

$2.75 \quad 4.72$

23 I am able to help students from diverse cultural backgrounds succeed in school by building their confidence in their academic ability.

$4.60 \quad 6.23$

24 I understand how to include and provide access to unbiased learning resources in order to help students' academic success.

$4.06 \quad 6.00$

25 I use culturally familiar examples to help make learning new concepts easier.

$3.56 \quad 5.81$

26 I display students' pictures and projects in the classroom because I know that this helps them develop a positive self-identity.

$4.02 \quad 6.00$ 
When comparing the responses of undergraduates and graduates the results were similar; however, graduate students tended to rate themselves higher than undergraduates on the pretest, but lower than undergraduates on the posttest as evidenced in Table 3. This may be in part because they have more life and perhaps classroom experience that enables them to more accurately assess themselves, but we do not have data to confirm this.

Table 3

A comparison of the average responses of graduate and undergraduate students on the pre and posttests for Sections II (CRTSE) and III (CRTOE) of the survey

\begin{tabular}{lcccc}
\hline Student Level & Section II Pre & Section II Post & Section III Pre & Section III Post \\
\hline Graduate & 4.18 & 5.71 & 4.22 & 5.79 \\
Undergraduate & 3.70 & 5.84 & 3.77 & 5.95 \\
\hline
\end{tabular}

When examining the TCs pre and post self-evaluation ratings on the CRTSE Scale, it is interesting to note that they felt quite confident in their abilities to build positive and trusting relationships with their students on the pretest and even more so on the posttest (questions 9 and 20). It appears that over the course of the semester and perhaps after participating in this project, the TCs felt better equipped to inventory and use students' cultural backgrounds, experiences and learning preferences to inform their teaching and enhance student learning (questions 13, 17, 29, 34, 36, and 38).

On the pre and posttest CRTOE scale, the teacher candidates again expressed confidence in their abilities to develop positive and trusting relationships (questions 1 and 16). Also of interest is that TCs judged their ability to design and teach lessons that include the cultural contributions the cultures of the students have made over time to help students develop an appreciation of their heritage (question 11) quite low on the pretest (2.73) with a substantial increase on the posttest (5.34). Since this was explicitly modeled in the methods class, it seems logical to assume that participation in this project directly impacted TCs' response to this question. It also appears that at the end of the semester the TCs were very confident in their abilities to motivate students to learn (question18).

Teacher candidates were invited to share their thoughts about participating in this project. Some common themes emerged from the feedback. The teacher candidates indicated that:

- The art project allowed them to express themselves and provide ideas for helping students in the classroom to do the same. 
- They realized the importance of connecting other cultures to the lessons, and examining how everyone has similarities and differences, but all have value.

- They discovered that CRT could be infused into content areas, such as geography and history, because it allows them to find out where students or their families came from and what their history is.

- They found the project to be fun and helped them get to know each other better in the methods class.

- They liked discussing other people's cultures and backgrounds and helped everyone appreciate who their classmates are.

- They expressed a desire to incorporate CRT into future lessons and teaching.

- They thought having a real art teacher made the art project more meaningful.

- The book talks helped provide context for introducing and exploring strategies for being a culturally responsive teacher.

- The project helped them become more aware of CRT in the classroom and lessons.

- They also expressed a desire to be aware of the needs of students before planning lessons.

- They did not initially see many CRT activities demonstrated in the classrooms in which they were interning so they created and implemented activities and strategies to use with students.

Students' written comments about the experience also demonstrate that they see the value in culturally responsive teaching and realize it will be a lifelong journey. One teacher candidate wrote, "I think I have a long way ahead of me to meet my goals [of becoming more culturally responsive]. I think we need to spend more time learning other ways to become culturally responsive teachers." Another preservice teacher stated, "I feel that I have made progress toward my goals and towards the teaching aspect of culturally responsive teaching. I have received great ideas on how to implement culturally responsive teaching into my classroom."

\section{Discussion and Implications}

It is a daunting task to prepare preservice teachers for the demanding job of teaching students from diverse backgrounds, ways of life and knowing, that are so different from their own. This study was an initial attempt to infuse culturally responsive pedagogy in a methods course as well as assess the impact on teacher candidates' perceptions about their own knowledge, skills, and competencies. While it is important to demonstrate and teach culturally responsive strategies and skills, it is critical that preservice teachers develop a sense of efficacy about what they know and can apply in their own classrooms. The results of this study 
indicate that students are able to self-assess these skills and perceive personal growth over the course of just one semester.

The results of this initial study align with Bandura's (1977) work and indicate that TCs' beliefs about their abilities to execute CRT strategies and to achieve the desired positive outcomes improved over the course of the semester and will hopefully increase the possibility that they will implement these practices with their own classrooms. These preservice teachers expressed confidence in their abilities to develop positive and trusting relations with their students. The research on CRT indicates that this is a critical component of effective culturally responsive teaching (Bennett, 2008;Brown, 2004; Wlodkowski \& Ginsberg, 1995).

This study was limited in scope but holds promise. Although teacher candidates were assured anonymity and no grades were related to their responses, they may have been reluctant to admit to a lack of belief in their abilities in certain areas because one of the researchers was responsible for the final grades in the methods class. Additionally, there are always inherent problems with self-rating in any study as one's perception may be very different than reality. Another problem may be in the rating scales themselves. Just what distinguishes an 89 from a 90 or a 74 from a 75 ? Even though students were told to think of in terms of percentages, perhaps descriptors such as "very confident" or "not confident" on a four point scale might prove to be more effective at capturing preservice teachers' thoughts about their abilities and skills to be truly culturally responsive in their teaching. Despite limitations, this study provides some evidence that attempts to infuse culturally responsive teaching practices in methods classes can indeed effect change in TCs' selfefficacy and expectations for successful outcomes.

This study involved one literacy methods course. It seems that the logical next step would be to expand this project to other content areas such as math and science as a natural progression to infusing CRT across the entire elementary education curricula. The survey proved to be an effective instrument for students to gauge their knowledge of and ability to teach in a culturally responsive way. It also prompted students to ask themselves important questions about what they know, what they can do, and where they want to proceed. The survey would be an excellent tool to use at the beginning of a preservice program and again at the end, because after the initial administration, teacher candidates begin to develop an awareness of what is involved in becoming a culturally competent and responsive educator. This provides a path for teacher candidates to follow as they begin their journey and gives them a direction and a goal for which to strive. Then, the methods courses and field experiences can be structured in ways that help them realize the goal of being truly responsive to all students. 


\section{References}

Bandura, A. (1993). Perceived self-efficacy in cognitive development and functioning. Educational Psychologist, 28(2), 117-148.

Bandura, A. (1997). Self-efficacy: The exercise of control. New York, NY: W. H. Freeman and Company.

Bennett, M. M. (2008). Understanding the students we teach: Poverty in the classroom. The Clearing House, 81(6), 251-256.

Brown, D. F. (2004). Urban teachers' professed classroom management strategies: Reflections of culturally responsive teaching. Urban Education, 39 (266), 266289.

Gay, G. (2000). Culturally responsive teaching: Theory, research, and practice. New York, NY: Teachers College Press.

Hilliard, A. G. (1998). SBA: The reawakening of the African mind. Gainesville, FL: Makare.

Jones, S. J. (2007). Culturally responsive instruction. Leadership, 14-18.

Joyce, B., Weil, M., \& Calhoun, E. (2009). Models of teaching. Boston, MA: Pearson Education.

Levine, E. (2007). Henry's freedom box. (K. Nelson, Illus.). New York, NY: Scholastic.

Ringgold, F. (1991). Tar beach. New York, NY: Crown.

Sammons, C. C., \& Speight, S. L. (2008). A qualitative investigation of graduate-student changes associated with multicultural counseling courses. The Counseling Psychologist, 36, 814-838.

Siwatu, K.O. (2007). Preservice teachers' culturally responsive teaching self-efficacy and outcome expectancy beliefs. Teaching and Teacher Education, 23, 1086-1101.

Wlodkowski, R. J., \& Ginsberg, M. B. (1995). A framework for culturally responsive teaching. Educational Leadership, 17-21.

Achenbach, K., \& Arthur, N. (2002, Winter). Experimental learning: Bridging theory to practice in multicultural counseling. Guidance and Counseling, 17(2), 39-45.

Arthur, N. (2001). Using critical incidents to investigate cross-cultural transition. International Journal of Intercultural Relations, 25, 41-53.

Association of Teacher Educators. (2007). Standards for teacher educators. Retrieved from http://www.ate1.org/pubs/uploads/tchredstds0308.pdf

Babbie, E. R. (1990). Survey research. Belmont, CA: Wadsworth Publishing.

Banks, J. A., \& Banks, C. A. M. (2006). Multicultural education; Issues and perspectives (6th ed.). Belmont, CA: Wadsworth Publishing.

Barrera, I., \& Corso, R. M. (2002). Cultural competency as skilled dialogue. Topics in Early Childhood Special Education, 22(2), 103-113.

Capella-Santana, N. (2003, Jan/Feb). Voices of teacher candidates: Positive changes in multicultural attitudes and knowledge. The Journal of Educational Research, 96(3), 182-190.

Connelly, F. M., \& Clandinin, D. J. (1990). Stories of experience and narrative inquiry. Educational Researcher, 19(5), 2-14. 
Darling-Hammond, L. (2007). The flat earth and education: How America's commitment to equity will determine our future. Educational Researcher, 36(6), 318-334.

Delany-Barmann, G., \& Minner, S. (1996, Summer). Cross-cultural workshops and simulations for teachers. The Teacher Educator, 32, 37-47.

Dixon, J. C. (2006, June). The ties that bind and those than don't: Toward reconciling group threat and contact theories of prejudice. Social Forces, 84(4), 2179-2204.

Festinger L., Schachter S., \& Back, K. W. (1950). Social pressures in informal groups: A study of human factors in housing. New York: Harper.

Ford, M. (2004). Considering the standpoints of differently situated others: Teachers and arrogant perception. Philosophy of Education Yearbook, 337-345.

Fowler, S. M. (1986). Intercultural simulation games: Removing cultural blinders. New Directions for Continuing Education, 30, 71-81.

Friedkin, N. E. (2004). Social cohesion. Annual Review of Sociology, 30, 409-425.

Gallavan, N. P. (in press). Navigating cultural competence. Thousand Oaks, CA: Corwin Press.

Gallavan, N. P. (2007). Seven perceptions that influence novice teachers' efficacy and cultural competence. Praxis: The Center for Multicultural Education, 2(1), 622.

Gallavan, N. P. \& Webster-Smith, (in press). Self-assessment: Analyzing reflectivity with candidates. In Association of Teacher Educators (Eds.) The purposes, practices, and professionalism of teacher reflectivity: Insights for 21 st century teachers and students. Lanham, Maryland: Rowman \& Littlefield.

Gay, G. (2000). Culturally responsive teaching: Theory, research, \& practice. New York: Teachers College Press.

Harry, B. (2008, Spring). Collaboration with culturally and linguistically diverse families: Ideal versus reality. Exceptional Children, 74(3), 372-388.

Karim, A. (Sept/Oct 2003). A developmental progression model for intercultural consciousness: A leadership imperative. Journal of Education for Business, 79(1), 34-39.

Lincoln, Y. S., \& Guba, E. G. (1985). Naturalistic inquiry. Beverly Hills, CA: Sage.

Marbley, A. F., Bonner, F. A., McKisick, S., Henfield, M. S., Watts, L. M., \& Shin, Y-J. (2007). Interfacing cultural specific pedagogy with counseling: A proposed diversity training model for preparing preservice teachers for diverse learners. Multicultural Education, 14(3), 8-16.

Moll, L. C., Armanti, C., Neff, D., \& Gonzalez, N. (1992). Funds of knowledge for teaching: Using a qualitative approach to connect homes and classrooms. Theory into Practice, 31(2), 132-141.

National Council for Accreditation of Teacher Education. (2008). Professional standards for the accreditation of teacher preparation institutions. Washington, DC: Author.

Pedersen, P. B. (2003). Multicultural training in schools as an expansion of the counselor's role. In P. B. Pedersen \& J. C. Carey (Eds.), Multicultural counseling in schools, (pp. 190-210). Boston: Pearson Education.

Schön, D. A. (1987). Educating the reflective practitioner. Paper presented at the annual meeting of the American Educational Research Association. Washington, DC. 
Shulman, L. S. (1987b). Knowledge and teaching: Foundations of the new reform. Harvard Educational Review, 57, 1-22.

Sleeter, C. (2009). Developing teacher epistemological sophistication about multicultural curriculum: A case study. Action in Teacher Education, 31, 1, 3-13.

Thiagarajan, S. (1984). BARNGA: A flexim on cultural clashes. Bloomington, IN: Instructional Alternatives.

Volkema, R., \& Rivers, C. (2008, Jan/Feb). Negotiating on the Internet: Insights from a cross-cultural exercise. Journal of Education for Business, 83(3), 165-172.

Webster-Smith, A. (2008). Examining the role of diversity in school dynamics: An internship that helps to meet NCATE Standard 4. International Journal of Educational Leadership Preparation. http://cnx.org/content/m16317/latest/.

Webster-Smith, A. (2008). Roots and wings: A self examination of familial influences that ground diversity leadership and an assignment that lifts it. International Journal of Educational Leadership Preparation. http://cnx.org/content/m16315/1.1/.

Webster-Smith, A. (2008). Monitoring teacher knowledge, skills and dispositions for culturally responsive pedagogy: An internship experience that helps to meet NCATE Standard 4. International Journal of Educational Leadership Preparation. http://cnx.org/content/m16607/latest/. 